\title{
Ethical Issues of Radio Frequency Identification Chips Implanted in Human Bodies: A Review
}

\author{
Muhammad Nadeem Akhtar ${ }^{1, *}$, Muhammad Adrees ${ }^{1}$, Muhammad \\ Mukhtar Qureshi ${ }^{2}$ and Zulfiqar Ali $^{3}$ \\ 'Department of Computer Science \& Information Technology, The University of \\ Lahore, Lahore, Pakistan \\ 2The University of Faisal Abad, Alam Tower Sub Campus, Lahore, Pakistan \\ 3 University of Central Punjab, Sialkot Campus, Pakistan
}

Article Type: Review Article

Article Citation: Muhammad Nadeem Akhtar, Muhammad Adrees, Muhammad Mukhtar Qureshi, Zulfiqar Ali. Ethical issues of radio frequency identification chips implanted in human bodies: a review. Indian Journal of Science and Technology. 2020; 13(03), 269-276. DOl: 10.17485/ijst/2020/ v013i03/147192

Received date: September 9, 2019

Accepted date: December 10, 2019

*Author for correspondence: Muhammad Nadeem Akhtar nadeem.akhtar@cs.uol.edu.pk 9 Department of Computer Science \& Information Technology, The University of Lahore, Lahore, Pakistan

\begin{abstract}
Objectives: This study belongs to the overview of an IT innovation technology known as "Radio Frequency Identification" (RFID) and its implantation in human bodies. Methods/analysis: This study provides critical analysis and review on ethical issues of RFID chips implanted in human bodies. Although there are some certain benefits to use this innovation in human bodies but on the other side its usage has very severe health impacts on human life. This study deals with RFID ethical issues, boundaries and constraints which confined its use. Findings: The major outcome of this study is to discuss and highlight these ethical issues and challenges due to which the deployment and implementation of this technology has become a controversial and debatable issue. Also focus on "legislation deficiencies" lying in RFID usage and suggest recommendations to improve it, so that its usage may continue for the betterment of mankind. Novelty /improvement: This article provides cutting edge knowledge on ethical issues of RFID chips implanted in human bodies for researchers of this domain.
\end{abstract}

Keyword: RFID Legislation, Ethical Issues, Chip Implantation.

\section{Introduction}

Now a days information technology (IT) has created a revolution in our life. This impact of IT can be seen in every area of human life. New IT innovations have changed the way of our daily working. Radio Frequency Identification (RFID) chip is one of such innovations, which has provided a new horizon to its users. RFID chips are used in increasing the productivity and convenience in human work. Applications of RFID can be seen in the prevention of automobile theft, toll collection without stopping the vehicles, traffic management, getting entrance into buildings, tracking books in libraries, animal medication, etc. 
RFID technology main purpose is to communicate digital information between movable objects and stationary locations. Various radio frequencies are used in RFID ranging from $100 \mathrm{KHZ}$ to $300 \mathrm{GHZ}$.

In RFID generally, simple kind of devices is used on one side called "tags" or "transponders" and on the other side some complex kind of devices are used called "readers", "beacons" or "interrogators" which are more capable to perform computation and mostly connected with host computers in a network.

First section of this study is about RFID basic introduction, its early development history, general application areas, hardware architecture, frequency bands on which this technology works. Second section is a discussion about RFID usage in human bodies. Third section deals with ethical issues and challenges occur due to this chip implantation. Fourth section discussed about legislation regarding RFID usage and its deficiencies. Last section concluded the study with some recommendations.

\subsection{RFID Early History}

Early invention of RFID chips started in the decade of the 1940s, when in World War II radar was refined and used; the first RFID chip was invented in 1948. In the decade of 1950s, RFID initial explorations and laboratory experiments were conducted. Then between 1960s and 1970s theory of RFID was developed and field trials of applications started. In the decade of 1970s to 1980s radical breakthrough occurred in RFID development. Test cases of RFID accelerated and initially this technology was implemented. Between 1980s and 1990s, RFID's commercial applications came into mainstream. From 1990 to 2000, RFID standards emerged, and this technology was deployed widely and it became a part of human's life. From 2000 onwards explosion of RFID is continued and it has been induced in many areas of our life [1].

The last two decades applications of RFID chips can be observed in various areas like supply chain system, transportation business (in the form of monitoring performance of vehicles, electronic license cards, computerized tool system, E-credit card, computerized identification of vehicles), in medical (in the form of patient history identification and monitoring).

Due to industrial convergence on standards, which results to reuse these tags at decreased cost, new applications in some new areas are being developed like, employing RFID readers statically in transportation industry, facilitated car rental companies to automatically monitor and update their inventory. Airline industry also exploit static reader by embedding RFID tags in luggage labels to automatically inspection, which eliminated manual inspection of billions of passenger's luggage/bags. This sort of action saved a lot of time and cost of airline companies [2].

Currently usage of these RFID chips in human bodies is a great development in the field of ubiquitous computing, but here are some emotional, ethical, and health-related issues like: reliability, ease of use, minimally obtrusive technology, which should be considered using these tags. People should feel comfortable physically and mentally while implanting these tags in their bodies [3]. 


\subsection{RFID Technology Components}

RFID system made up from three main components, RFID transponder/Tag, Reader, RFID Middleware.

\subsubsection{RFID Transponder/Tag}

RFID transponder consists of antenna and chips. Chips store a serial number in which the data of the product are stored. The data are read and write in these chips, write one time and read countless time from it. The antenna is used for transmitting information from chip to reader and this information can also be scanned. There are three types of tags. Passive, Active, and Semi Passive/ Semi Active. Passive Tags does not have own power source and they itself cannot communicate with reader because of unavailability of battery. Passive Tag operates at low, high, ultra high, and microwave frequencies. Active Tags contain their own power source and they can communicate to the transmitter and chips. Semi Passive/ Semi Active cannot communicate with the reader, but contain power source that allow the tag to perfume communication and their function.

\subsubsection{RFID Reader}

RFID reader is like a scanning device that reads the tag and communicates to middle ware. Reader can be mobile or stationary. There is one master part of the reader, which performs three functions like supply power to tag for generating high frequency, then modulate it and finally demodulate all of the tags. The other component of reader is a control unit their function is to enable the encoding and decoding of signals and also provide communication control with tags.

\subsubsection{RFID Middleware}

Middleware lies between hardware components and software which connects the reader and data collected from tag. It applies different techniques on tags and detects them for delivering data and communication. It supports multiple synchronization, hardware, scheduling, real time data handling, and interfaces with applications [4].

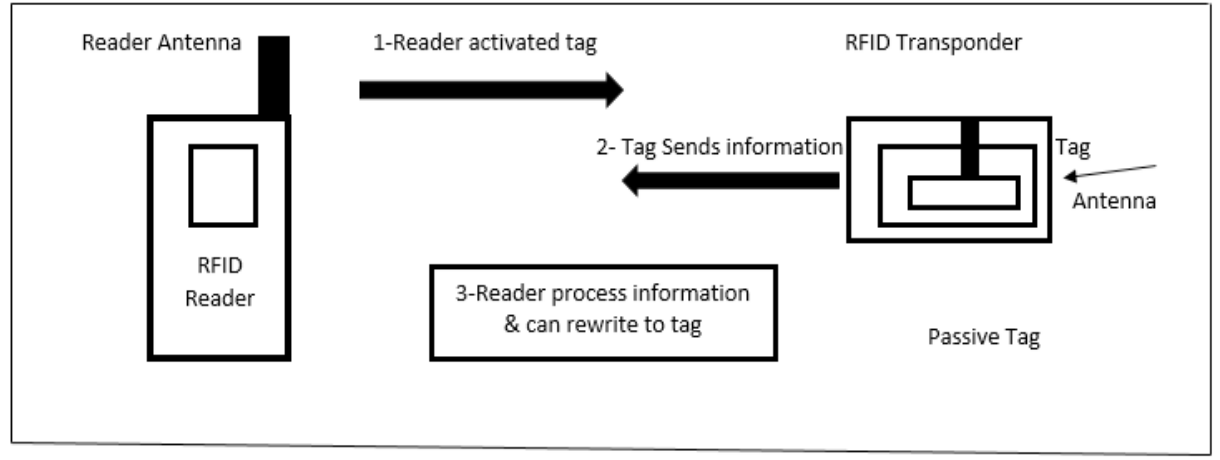

FIGURE 1. RFID reader and tag communication [4]. 


\subsection{RFID Technology Frequency Bands}

The bands being used for Radio Frequency Identification are as follows:

Low Frequency - Range from $(125 \mathrm{KHz})$ most commonly used for animal tracking, access control to buildings, asset tracking, and cargo shipping.

High-Frequency - Range from (13.56 MHz) used where medium data rate is required can read ranges up to 1 meters. This frequency is not sensitive to the presence of water or metals, which is the unique property.

Ultra High-Frequency - IBM engineers developed UHF bands range from (433 $\mathrm{MHz}$ to $2.45 \mathrm{GHz}$ ) offering the longest reading range up to the 20 feet (in good conditions). It is widely used nowadays. It is easy for tracking consumer products.

Micro wave Frequency - Range from (2.4 GHZ to $300 \mathrm{GHZ})$ and can read data from 2 + meters [4-6].

\section{Discussion about RFID Implantation in Human Bodies/Chipping}

RFID chips applications and usage in material objects is appreciable and it has not any negative impact on human's life, but its implantation in human bodies which is called "chip implants or chipping" is a controversial issue. This concept has divided RFID users in two segments/groups, one who are in favor of this procedure and others who are against these implantations. These chips are inserted in human bodies by surgery.

This "chip implantations" in human started first time in 1998 when British scientist Kevin Warwick got an RFID chip in his body through invasive surgery. His implantation was for opening the doors, on/off light switch. That chip remained in the Warwick's body for 9 days, after that it was removed from his body and since then is placed in science museum London [7].

Both groups have their own views one in favor and other against of this "chipping" and it will be unfair to discuss only one side views either it is in favor or against. So we will discuss some of the cases of applications/usages of these "chip implantations" related to both groups.

In 2004 Food and Drug Administration (FDA) which is a medical devices regulatory body in the United States, approved RFID tags in human bodies for accessing health records of peoples. Veri Chip tags were used for this purpose which has a transponder relying on reader power for processing; it does not have its own power.

Veri Chip Corp. is basically a subsidiary of another company Applied Digital Solutions, its headquartered is in Delray, Fla, USA. It is promoting security measure devices. Veri Chip was a part of health-related information system called "Veri Med." Veri Chip high profile applications can be seen in 2004 when Mexico City's attorney general and his 18 staff members got implanted to access the certain high security areas.

In May 2006 Veri Chip CEO, Scot Silverman gave a proposal to US government in an interview with Fox news channel about chip implantation in immigrants and guest workers, to facilitate the US government in identification of coming peoples in their country. Later 
on a US senator became agree that for Colombian citizen it would be necessary to be "implanted" with RFID chip to get entrance in US for the purpose of seasonal work. Social researchers have started to monitor and study people's attitude about RFID implantation, in this perspective a survey was conducted in Bridgewater State University, in Massachusetts, to 141 students on their feeling about RFID chip implantation, Respondent was asked questions, that will they be willing to be implanted to prevent their ID theft, to battle against terrorism, to insure the security and safety of themselves and their families? Onethird of them were willing to adopt this "implantation" while less than half were not willing to adopt this. The main reason of willingness of respondents was life security of themselves and their families [8].

According to the news reports in some trendy bars of Spain, Scotland, Netherland, and United States patrons can be "Chipped" at the door when entering, it enables waiter staff to recognize these patrons electronically to ensure their purchase [9].

Another application of RFID implantation can be seen in "Epicenter" which is Swedish company having their office in Stockholm, it is basically an innovator's company introducing new modern technologies and ideas, employees of this company mostly got implanted their hands to get facilities like to open office security doors, get photocopies pay lunch bills, it was estimated that very soon about 700 employees belong to hi-tech office block of this company will be implanted their hands using RFID chips. Because this company is pro-technology and it's mostly employee are young, they try new things, and are crazy about the usages of new technologies; they took all this sort of action proactively [10].

\section{RFID Ethical Issues/Challenges}

RFID chip implantations in human bodies have created some ethical questions/issues, which need to be discussed as well as solve, like some issues regarding compulsory RFID chip implantation in US immigrants or guest workers (by the US government to get entrance in country) are discussed here:

Either these immigrants or guest workers "truly voluntary" accept this "implant" or they have to adopt to get jobs or visa?

Suppose if they become agree for this implantation, most of them are poor guest laborers, who will pay the cost of this purchasing, implantation, and monitoring of hundreds of thousands such chips?

There are also chances of adverse reactions of these chips in the human body, if such situation occurs who will remove these chips?

If these chips become obsolete and are compromised by the rampant cloning who will pay?

So Silverman's proposal that "immigrants and guest workers should be implanted" became a national debate in the United States.

As mentioned in the previous section, if government enforce their citizens for societal benefits to be implanted just for the security of their families and themselves now an ethical question arise either it is correct for government to modify someone individual's bodies? [8]. 
After implantation of RFID chips in millions of animals, these chips seem to pose some medical risks on human as well, the FDA in 2004 listed some of the potential risks as hazards like, adverse kind of tissue reaction, implanted transponder's migration, negotiation in information security, implanted transponder's failure, failure of inserter, electronic scanner failure, electromagnetic interference, electrical hazards, imaging incompatibility, magnetic resonance, and needle stick. All these hazards are vitally critical and need proper legislation to tackle all these [9].

As mentioned in Ref. [10] about chip implantation in hands of "epicenter "employees, though most of the young employees are in favor of this, but still it creates an ethical issue about pain which employees feel during this chip insertion in their hands, if employee change the job then will have to remove that chip from their body, some employee may feel it painful for them to go in this process again and again. If employee does not remove this chip from his/her hand, it will not be ethically right for employee, to steal company secure data, especially once he/she is not part of that organization [10].

Veri Chip which is majorly approved by FDA for patient health-related record identification is also vulnerable to simple "cloning" attack, exclusively security systems relying on Veri Chip authentication - like physical access control system and payment system. Its consequences are very serious in the form of cost as well as system's security. Veri Chip is recommended to use only to identify their bearers, not to authenticate them. Although in Ref. [11], author proposed and designed another RFID tag called "iChip" that emits identifier through simple cryptographic scheme and this helps to protect the privacy but at the same time expressly enable straight forward cloning, still there is need to further improve security of Veri Chip [11].

Another key issue of using the RFID tags is the privacy of personal data and information and the ability to read data and use against them. For example, if a person get some antidepressant medicine from a local store that uses RFID tags that he keeps it in his bag. After this he goes for a job interview, and the company also uses the RFID tags, so the employer can easily read the tags of his medicine and could not hire him/her just because of his/her usage of antidepressant medicines. One can notice that the data of the consumer can be used by the medicine company too. These data can be shared by Advertisement Company to show that particular consumer using their product in the advertisement. So there should be a level of trust between a company and consumer. Sometimes people do not concern about providing their personal data to any company on which they trust, but they are much concern about the publication of their private data to cloud. These data can also be misused by anyone, or there is a chance that data can be manipulated and consumer gets loss from them. This issue has been highlighted at different forums such as a clearinghouse of privacy published a "RFID position statement of Consumer Privacy and Civil Liberties Organization”. Consumer against Supermarket Privacy Invasion and Numbering was of another organization that signed onto that statement. One of the US Senator also addressed this issue in the US parliament [12].

While using RFID tags in health care domains, a user has to share those tags with his/ her doctor, physician, or the pharmacist that my lead again to a lot of privacy and loss of personal data issues, for example, they can trace their personal geographical location or health information. There is a need for a proper legislation to provide the control process. 
As in Ref. [13], author discussed an access control technique for the privacy preservation to restrict an unauthorized person from accessing the data or personal information [13].

\section{Legislation on RFIDs}

RFID implantation in human needs proper legislation to deal its ethical impacts. In this perspective, some countries of the world deal this phenomena from a legal point of view, like Issue of RFID chip implantation in Immigrant and guest works of US is widely against the basic human rights and is a violation of Article 3 of the United nations' Universal Declaration of Human Rights, which affirms everybody's right to "life, liberty, and security of person. Since 2002 about seven hundred documents have been published on this controversial issue. In the US more than 10 enacting laws exist to restrict and allow transparent usage of these implantations. In May, 2006 Wisconsin passed bill which restrict to requiring someone to get implanted by microchip [8].

In 2007, American Medical Association (AMA) designed special code of ethics regarding patients who receive RFID chip implantations. Major emphasize of AMA's recommendations was on protection of privacy and health security of patients. AMA's Council on Ethical and Judicial Affairs (CEJA) formulated these recommendations. The main purpose of these recommendations was to solve the privacy and security of patients implanted chips [14].

In Ref. [15], a bill named "RFID Right to Know Act of 2003" was presented by the Caspian. It not only covers the demands of consumer and business education, but also instructs the Federal Trade Commission to issue and distribute documents in order to educate companies on RFID technology and the importance of protecting the privacy of individuals. These documents should explain RFID technology in detail and also advocate the protection of privacy. They should also explain how companies make their actions, corresponds to comply with the provisions of this Act [15].

\section{Conclusion}

As long as modern technologies are emerging and new innovations are occurring day by day, the scope of RFID chips is bright. It is expected that in near future the concept of carrying money, even plastic money in the form of ATM or credit/debit cards will be reduced, due to these chip implantations in human bodies. Because all kind of business and financial transactions will become possible through this technology, but still this technology have "darker" as well as "brighter" side. We cannot say clearly that its usage is hundred percent safe, in good favor of humans or not safe, is vulnerable, fatal for human life. So it is debatable and controversial issue. Technology innovators are in great favor of it, but people like social scientists are against its usage. To reduce the vital risks of RFID chip implantations in human bodies, Veri Chip is optimistic to provide no invasive RFID chips. As nonprofit healthcare informatics organization medical alert is searching such kind of bracelets which are RFID enabled and can provide patient's health records. If people's concerns about adverse effects of RFID implantations, like security, privacy, health-related 
issues as discussed in this study previously are deal properly, and some further refinement in its laws is made, then technology itself is not bad, its usage should be continued for the betterment of mankind.

\section{References}

1. Landt J. The history of RFID. IEEE Potentials. 2005; 24(4), 8-11.

2. Nath B, Reynolds F, Want R. RFID technology and applications. IEEE Pervasive Computing. 2006; 5(1), 22-24.

3. Pantelopoulos A, Bourbakis NG. A survey on wearable sensor-based systems for health monitoring and prognosis. IEEE Transactions on Systems, Man, and Cybernetics, Part C (Applications and Reviews). 2009; 40(1), 1-2.

4. Shoewu O, Badejo O. Radio frequency identification technology: development, application, and security issues. The Pacific Journal of Science and Technology. 2006; 7(2), 144-152.

5. The history of RFID technology. https://www.rfidjournal.com/articles/view?1338. Date accessed: 2005.

6. Al-Ali AR, Aloul FA, Aji NR, Al-Zarouni AA, Fakhro NH. Mobile RFID tracking system. In: 2008 3rd international conference on information and communication technologies: from theory to applications. 2008, 1-4.

7. Is human chip implant wave of the future? http://edition.cnn.com/TECH/computing/9901/14/ chipman.idg/. Date accessed: 14/01/1999.

8. Foster KR, Jaeger J. RFID inside. IEEE Spectrum. 2007; 44(3), 24-29.

9. Foster KR, Jaeger J. Ethical implications of implantable radiofrequency identification (RFID) tags in humans. The American Journal of Bioethics. 2008; 8(8), 44-48.

10. Emotional design in wearable technology. https://digitalwellbeing.org/wp-content/uploads/ 2015/11/2015-Emotional-Design-in-Wearable-Technology.pdf. Date accessed: 09/3/2015.

11. Halamka J, Juels A, Stubblefield A, Westhues J. The security implications of VeriChip cloning. Journal of the American Medical Informatics Association. 2006; 13(6), 601-607.

12. Turri AM, Smith RJ, Kopp SW. Privacy and RFID technology: a review of regulatory efforts. Journal of Consumer Affairs. 2017; 51(2), 329-354.

13. Rahman F, Bhuiyan MZ, Ahamed SI. A privacy preserving framework for RFID based healthcare systems. Future Generation Computer Systems. 2017; 72, 339-352.

14. AMA issues ethics code for RFID chip implants. https://www.rfidjournal.com/articles/ view?3487. Date accessed: 17/07/2007.

15. Riding the wave: the uncertain future on RFID legislation. https://scholarship.law.nd.edu/cgi/ viewcontent.cgi?article=1048\&context=jleg. Date accessed: 01/01/2009. 